\title{
Re-Thinking Bloomfield's Concepts of Meaning: Do Meaning Really as a Weak Point in Language Study?
}

\author{
Cendy Lauren ${ }^{1}$ Anggi Resti Rahmadani ${ }^{2}$, and Farni Wulandari ${ }^{3}$ \\ ${ }^{1}$ SMA Negeri 2 Tambang, Kampar, Indonesia \\ ${ }^{2}$ SMK Negeri 3 Pekanbaru, Indonesia \\ ${ }^{3}$ SMK Negeri Pertanian Pekanbaru, Indonesia \\ laurencendy@yahoo.com
}

\section{ARTICLE HISTORY \\ Received : 2019-12-02 \\ Revised : 2019-12-04 \\ Accepted : 2019-12-27}

\section{KEYWORDS}

Meaning

Linguistic,

Behaviourist

Context of situation

Weak point

\begin{abstract}
This paper aims to describe the concepts of meaning in Bloomfield's Theory. The methodology used to gain data in this paper is a qualitative descriptive using documentation method. Sources of data consists of words, sentences, and discourses found in the book Language by Bloomfield published by Henry Holt in New York in 1933. This research collects its data in a descriptive manner by reducing data, presentation data then drawing conclusions. The results of the analysis of this study indicate that Bloomfield underlines that meaning as a weak point in language study and believed that it might well be all expressed in behaviourist terms. Bloomfield also stressed the context of the situation was a very important level of linguistic analysis aside syntax, morphology, phonology, and phonetics, all of which support to linguistic meaning. This present study also found that Bloomfield considered words to be ambiguous notions both in everyday speech and in linguistics.
\end{abstract}

\section{Introduction}

Bloomfield's book Language has long been recognized as the framework for systematic descriptive linguistic analysis. Bloomfield found considerations of meaning to be important. His detractors find sense to exist outside of the individual speaker. Consequently, this paper does indeed define concepts of meaning in Bloomfield's Theory as low in language. The book was written by linguists, who was familiarly called by the name of the questioner Bloomfield, full of words explanation, linguistics and context related to social life. Language by Leonard Bloomfield is published by H.Holt, Rinehart and Winston in New York. The first copyright edition of the book was made in 1933 and digitized in February 2008. This book has 564 pages, and the ISBN is 0226-06067-5, ISBN 90-272-1892-7.

Nevertheless, he sought to use the principles of sense in practice. This definition deals with language relations and the connections between language and the outside world. The relations between language and the external world, concern the meaning of the language. Further, it is means in relation to situations to which language references or in which language occur. Language relations are connected with the lexical element (word) and with the lexical structure, whose analysis is known as lexical or structural semantics. Many types of research, such as generative grammar studies omitted the relationship between language and the environment.
Linguists typically describe semanticization as a theoretical nature study. The Merriam-webster dictionary describes semanticizes as an analysis of language meanings and phrases. Semantic is historically characterized to research the meanings of words. It is the term frequently used by linguists. It means that if we want to study the importance of words, we must first study the semantic meaning of them. The words we use are considered to be part of the language understanding of an individual and part of the grammar. Words may offer different meanings depending on different kinds of situation.

In addition to being a linguist, Bloomfield is also famous for the behavioural theory, which suggests this mechanism culminates in imitation or mimetic process. Each pronounced word has a structure. For example, if a person was to call a house, the structure needed to be a house and not a hammer or angry. He uses oral language as an object of study and establishes his descriptive language. About language and structure, Bloomfield discusses the principles of the structure analysis, namely the theory of decapitation.

While following Watson and Weiss ' flow of behaviourism, Bloomfield accepted a theoretical interpretation that was in line using Wundt's psychological theory. Then he opposed mentalism and studied the conduct or behavioural flow. This has greatly influenced American Linguistics development. With the behavioural models, 
Bloomfield describes the semantic sense. As a result, other linguists who are followers do not investigate the meaning. Based on the distribution of these elements in the setting where the elements are found, linguistic elements are clarified.

The formation of this flow is triggered by several factors. Among them, the linguists in America had the same problem at the time, namely a large number of Indian languages not spoken. They want to explain in a modern and synchronous way the Indian languages. The old method, traditionally or diachronically, is of little use and has doubtful effectiveness, since many are almost entirely unknown because the past of Indian languages is little known.

The stance of Bloomfield to reject mentalism corresponds to the intellectual environment established in America at that time, namely the theory of behavioralist. The flow of structuralism is, therefore, often based on facts that are self-objective and can be matched to tested truth. Nor is it shocking that there is no exposure to the problem of concept or concept. Apparently, there are American linguists who are strongly influenced by Bloomfield to go beyond meaning. Zellig S. Harris, for example, with his book Structural Linguistics. American structuralists ' aversion to this meaning depends on how it functions, heavily dependent on empirical data. The meaning cannot be empirically identified. Unlike phonemes, morphemes and words, which can be observed and segmented.

This study did a brief research on Leonard Bloomfield find that he was born in Chicago on April 1, 1887. He graduated from Harvard College at the age of 19 and continued his postgraduate studies at the University of Wisconsin for two years. In 1909, Bloomfield was awarded his PhD by the University of Chicago.

Leonard Bloomfield (1887-1949) was a renowned American structural linguist. It has a strong influence and is still felt today. He specializes in Sanskrit, Tagalog, General Linguistics and Literature. Language (1933) is his most influential book. A lot of students and supporters. C.F collected some of his research. Hockett at A. A. Anthology of Leonard Bloomfield. Bloomfield uses the idea of Ferdinand de Saussure in the study of language as the theory of analysis, specifically, in the language structure.

\section{Method}

Qualitative analysis is used to explain phenomena of what subject study encounters, e.g. behavior, perception, motivation, actions and others in a holistic way, and by means of words and languages explanations, in a specific natural sense and through the use of various natural methods. Therefore, investigators used a descriptive approach in this study.
Descriptive research studies in the form of peoples, organizations, or other observations put into certain phenomena or populations that the investigator obtains from the subject. The goal is to clarify aspects relevant to the phenomenon observed and to describe the characteristics of the phenomenon or problem in hand.

Descriptive research generally does not use hypotheses (non-hypotheses) so that there is no need to formulate a hypothesis in his research. In descriptive research there are three types of methods, namely case studies or case studies, comparative causal research and correlation research, Suharsimi says. Investigators in this study use a case study approach to describe in detail and in-depth a history of certain objects or events. As Winarno said, case studies are a research method which focuses on a case intensively and thoroughly and consists of a case-bycase unit.

The data collected in this analysis is a tool for the data collection of data used to find data about items or factors in the form of notes, records, books, papers, newspapers, registry documents, meeting minutes, leggers, agendas etc. Researchers collect data, records or written reports of all activities in the forum through technical documentation. In this context, the researcher attempts to obtain information on deficiencies in the nature of Bloomfield's own understanding of value. The data analysis steps of the researcher are based on what Sugiyono has enriched as follows:

a) Reduction of results. Reducing data means summarizing, selecting the major things, concentrating about important issues, looking for trends and patterns with reduced data, giving the researchers a clear picture and encouraging the collection and quest for data when appropriate.

b) Presentation of data. The next stage is the presentation of data after the data has been reduced. And the presentation of data as a form of a short explanation, tables and the like in this analysis.

c) Withdrawal Conclusion. The third step in quality data processing is the conclusion of the withdrawal. The qualitative research conclusions must be backed by clear and reliable evidence so that the results are fresh, relevant findings that can address the problem.

The qualitative description used in this study also attempts to objectively, factually and reliably identify or depict the causes, characteristics and connections between the phenomena studied on the ethical side of social life. 


\section{Results: Bloomfield's Views}

\subsection{Meaning and Linguistics}

The statement by Bloomfield highlighted the role of meaning work in linguistics. The man utters a lot of vocal noise and makes use of the variety: he generates the types of stimuli that he produces certain vocal sounds, and his fellows make the right response, hearing these similar sounds. Only put it briefly in human discourse various tones have different meanings. Understanding this synchronization is understanding language with certain meanings of certain sounds. This synchronization helps man to communicate with high accuracy. (Bloomfield, p.27, 1933/2001)

This clear statement by Bloomfield's on the topic of language learn about reflects his more comprehensive view of language study than many believe it to be. For him, meaning is a part of language study that is inseparable. Linguistic study is not only concerned with the "biophysical aspect of language", sounds, and the "sound-producing movements and the resulting sound waves and the vibration of the hearer's eardrums", but also the "biosocial aspect of language", meaning, and how "the persons in a community have been trained to produce these sounds in certain situations and to respond to them by appropriate actions" (Bloomfield, 1939, p.8, quoted from Belyi, 1967/1999, p. 117).

People get through sound waves to each other that cause concrete behaviour. Language is not only biological and physical but also social and interpersonal; it is not only a physiological but also a sociological integration of sound and sense. Nevertheless, Bloomfield's pursuit of objectivism in linguistic research led him to rely too heavily on "scientific knowledge" (Bloomfield, 1933/2001, p.145) and "superficial interpretation of his mentalism and process discussions" (Fries, 1954/1999, p.86) led to the popular belief that Bloomfield avoided meaning analysis. But it is self-evident that in the book Language (1933/2001) he dedicated a whole chapter to language. He not only spoke about the concept of meaning in this article but also explored various types and aspects of meaning in detail.

The mentalist theory claims that the variation of human behaviour is due to the intervention of certain non-physical factors, spirit or will or mind (that) does not obey the patterns of succession (cause-and-effect sequences) of the material world; the mechanistic theory assumes that the variability of human behaviour, including speech, is only due to the fact that the human body is a very detailed one.

In all sciences such as linguistics, which study other kinds of human behaviour, a worker must proceed precisely as if he held a materialistic (mechanistic) view "(ibid), so Leonard Bloomfield recognized and clarified the variation of human behaviour as well as of speech as part of a sequence of causal and impact.

\subsection{Meaning and Behaviourist Term}

Now we will discuss the semantic principle of Bloomfield, which is behavioural. Based on the quote illustrates Bloomfield's behaviourist conception of meaning:

\begin{abstract}
"Psychology, in particular, gives us this series: to certain stimuli $A$ a person reacts by speaking; his speech $B$, in turn, stimulates his hearers to certain reactions C. By a social habit which every person acquires in infancy from his elders, $A-B-C$ is closely correlated. Within this correlation, the stimuli $A$ which cause an act of speech and the reactions $C$, which result from it, are very closely linked, because every person acts indifferently as a speaker or as a hearer. We are free, therefore, without further discussion, to speak of vocal features or sounds $B$ of stimulus reaction features A-C of speech" (1926: 154).
\end{abstract}

Example: We tend to imagine a situation A where someone receives stimuli, say, she feels hungry. Then, she might utter something like: "I am hungry!". The actual utterance is situation B, talk to Bloomfield. This utterance, then, can stimulate others to certain reactions, linguistic or non-linguistic, this is Bloomfield's C.

Bloomfield theory (1933) describes language as a motivation and response sequence. The external world provides an incentive, and the body responds in the form of an action that is spoken or performed. If you see a sadza plate, that's the stimulus. The response and therefore, the sense to ask or take and eat is. The theory correctly captures the notion of language and speech acts (Syal and Jindal, 1999).

Nevertheless, while the question of significance is properly addressed in speculation, it is accused of failing to clarify the sense of value (Mhute, et al., 2014). It was also argued that one argument could be made, but that different actions could be taken in reaction. For instance, if you're saying "Come here Chipo," you're not my boss, you're preparing for dinner, you're not my boss, and you're paying me first. The stimuli and the responses become so difficult to link unless there is some background information. It was also criticized for not explaining the meaning of a single word because it has nothing to do with stimulation and response.

\subsection{Meaning and Context of Situation}

The "meaning of a linguistic form" is defined as "the situation in which the speaker expresses it and its response" (Bloomfield, 1933/2001, p.145). This description tends to be in line with the above- 
mentioned quotations and Bloomfield's principal argument, namely that the meaning is sensitive events (some sensitive events in very specific circumstances that cause the speaker to utter the linguistic form and also the answer action on the part of the listener). And he chose to "discuss and explain the significance in terms of the stimulus of a speaker," because it "will usually be a simpler aspect than the response of the listener" (Bloomfield, 1933/2001, p.145). By this definition of meaning, Bloomfield should be understood to point out two important factors in human communication, that is to say, circumstances and participants which are crucial for generating and communicating meaning among people.

His additional exposure of the two main points of the definition of meaning, however, was so closely tied to his opposition to mentalism and the pursuit of scientific objectivity that he was suspected of having misunderstood his position on the study of meaning and even of diverting its followers from a serious linguistical study of meaning. Bloomfield highlighted the importance of scientific knowledge as to what means we can interpret the significance. The conditions that lead people to speak include every entity and event in their universe.

To give every form of language a scientifically accurate concept of meaning, we must have a scientifically accurate understanding of everything in the world of speakers. The real scope of human knowledge in relation to current knowledge is very limited. We may accurately define the definition of speech-form, while this definition may relate to some subject of which we have scientific knowledge. The names of minerals can, for example, be defined in terms of chemistry as if we are suggesting that the common meaning of the word salt is "sodium chloride (NaCl).".. (Bloomfield, 1933/2001, p.145)

One cannot deny that a part of the meaning of salt is absolute "sodium chloride," but it is not defined properly or adequately as such. As defined as a "crystalline compound $\mathrm{NaCl}$ made of sodium chloride, abundant in nature and especially for the seasoning or preservation of food or in the industry" (Merriam-Webster Dictionary), salt has not only a scientific identity but also a valuable significance. Therefore, the housewife will usually not have to regard "salt" as a "sodium chloride" chemical structure to grasp what "salt" stands for and for, which may well mean that in some instances the importance of salt's practical sense overrides the significance of its scientific composition.

Bloomfield, Firth (1957a) thought that the meaning of the term could not be fully understood in the context of the language situation. But the idea of Bloomfield goes far beyond Firth, who created statements of significance in terms of the situation. Bloomfield described the situation as meaning. For
Bloomfield, meaning should be composed in the relation between speech and the preceding and following practical events. A linguistic form is "the state where the speaker utters it and the answer in the listener" (1933, p. 20). This means that the linguistic meaning is "equivalent to the total amount of human knowledge (because) situations that cause people to speak every object or thing that occurs in their universe" (1933, p.74).

Therefore, understanding the meaning of every kind of speech in a language requires "a scientifically accurate explanation of everything in the sense of the speaker" (1933, p.139). Consequently, the meaning of language can only be clarified "if certain research, other than linguistics, has provided us with interpretations of words, and if it is not completely studied and described, the meaning of utterance is the weakest point in the analysis of languages, and remains so until human knowledge advances far beyond its present state" (1933, p.140). To date, Bloomfield is clearly suggesting that linguistics be limited until science can determine the meaning and generate it in solely compiled types. Bloomfield says that in the meantime "we are able to act as if science had evolved enough to understand the situations and the responses that make up the meaning of forms of speech" (1933, p.77).

Furthermore, Bloomfield recognizes that "everything includes things not discovered by science" (1933, p.75). Until science is able to define most definitions or show their continuity, Bloomfield said, "We must take the basic and subtle characteristics of the language as a presupposition of linguistic studies, just as we assume it in our everyday dealings. This presupposition may be the fundamental assumption of linguistics. Bloomfield agreed that this assertion is only true within limits, although its general reality is not only recognized in the language study but in all our real language use. Assuming that some connection gives each form a constant sense, the principle of continuous invention collides with it (cf. de Beaugrande, 1991, 4.23, p.65).

\subsection{Ambiguous Notions of Meaning}

Bloomfield suggests that words can be regarded as the least free units (Bloomfield, 1933). It means that terms should be used as the smallest unit in isolation. So it depends, of course, on whether the term is saying by isolation or separation. The words of, is, is and is not used separately. We use them in full with other phrases. Bloomfield also suggested that a smaller element than the word, a unit of meaning-a morpheme, should be looked up.-Berry In blackberry, for example, or $-y$ in Johnny, etc. Several linguists have drawn attention in words like loved ones to the morphemes. Within this word, we can identify loveand d-morphemes. In this case, the word lexeme was best defined. 
Lexeme is a scientific concept used by linguists frequently. The words are grouped under lexeme headings in dictionaries, i.e. there are no such headings for loving and loved words in dictionaries.

The main word is love, and under this heading, we will look into the word. This indicates we have interpreted the meaning of a word individually and the various elements, i.e. the plural form or simple forms from the past, must also be considered separately. The meanings of terms can be explained without dividing them into parts. But some problems can be dealt with when the components of meanings are defined. Terms can have no clear meaning if we break them into pieces. Bloomfield, for example, drew attention to the word cranberry. He said that the cran element has no independent meaning in this word and we cannot see it in other terms. Then it's like strawberries and gooseberries to explore those words. He said that the words "straw" and "goose" have no relation. However, some contradictory points are also present. For example, in the word blackberry the word black-doesn't have any relation yet blackretains its meaning in the words blackbird and blackboard.

The words greenfinch, bullfinch and chaffinch then make a fascinating trio as well. Such three terms express the meaning of finch green-in the word greenfinch it describes its colour, bull-in the word bullfinch there is no relation with the word; chaffinch has no significance with the term chaffinch. Such words are phonaesthetics in English because only one aspect of such words may provide information on meaning. For example, the words beginning with sl sometimes convey a "slippery" meaning. Slide, slide, slither, slush, sluice, sludge, etc. Some words beginning with sl-mean pejorative: slattern, slut, sly (hiyl, butter), slovenly and others. Some terms that begin with sk-convey the surfaces or surface: skip, skimp, skim, skin, etc. We can also see in the meanings of the words in the dictionaries that start with sn, str, sw, tw, etc. We are assured that we will follow the same type. Let us now look at the word list that ends in -ump. Nearly everyone expresses some sort of roundish mass, plump, chump, rump, kump, lump, bump, stump. We can also add a number of words to this list. Of course, not all words in English do not derive their meanings according to these phonological characteristics.

In words, we should know there is no sequence of somaticized combinations. So this investigation leads us to convey with different elements the meanings of the same words (Bloomfield, 1933). The distinction between clear words and opaque terms was created by Ullman (Ullman, 1962). Clearly defined are transparent words as we may assess its value through the context of its pieces. Opaque words are those whose significance from their context cannot be defined. For instance, words such as chopper and doorman refer to transparent words; words such as axis and porter are opaque words. If we pay attention, we can analyse that the meaning can be formed by connecting a few words. Examples can be given of phraseological units, idioms, etc. Let's look at a few idioms since we know that the meanings of languages cannot be predicted by the meanings of their words.

For example, fly the hands off (to get angry), spill the beans (to expose a secret), red herring (false story) and so on. The definitions of the idioms, as we know, frequently vary from the meanings of the words that form them. When using the idioms in the sentence, we need to be careful. Single units are thought to be idioms. Yet they're not singular grammatical units semantically. For example, to form the past unlimited tense shape of the idiom "fly of the handle" we add the suffix -ed not to the last word as a single grammatical unity its past tense shape flew from the handle (not the handled fly). When we investigate, we know that semantic division often overrides word division.

For example, let us use the words pretty dancer and good singer in the sentences.

(1) My sister is a pretty dancer;

(2) This woman is a good singer.

Semantically the word pretty+dancer doesn't mean "a pretty dancer," it defines the one who dances beautifully. Similarly, in the term good+singer, the definition is not "the good singer," but the good singer. When we try to keep the comparison and make changes, the interpretation will be like this beautiful dance and good singing for these problems. The criteria for this are grammatical ambiguity (Bloomfield, 1933).

\section{Discussion}

The general position of linguists is that the importance of language study is really a weak point. The importance is still a controversial matter. Nevertheless, as mentioned above, a close examination of the above-mentioned theories and their shortcomings reveals that they concentrate on various aspects of the principle in question. In Linguistic, the meaning is sound stress when people talk to someone, which the phrases have a lot of meaning, and every sound stress is also important.

The definition interacts with the concept of behaviour, as people talk on the basis of their daily habits, societies, the activities. Also, the term of actions provides a stimulus, and the body provides a response in the form of action either said or performed. Thus, meaning depends on the situation and sometimes it creates a double sense in the thought of the person. It becomes confusing for everyone when people say they cannot clearly understand the meaning of the phrases or terms. 


\section{Conclusion}

The results and discussions of this paper described by the author as meaning the relationship between the sound symbol and the reference. Meaning is a form of stimulus response obtained by the actor in communication in accordance with the association and learning outcomes assessed. For Bloomfield, the meaning is a part of a language study that is inseparable and interconnected. In a linguistic study where meaning was given to how "people in a community were trained to produce these sounds in certain situations and to respond to them by appropriate action" (Bloomfield, 1939, p. 8, cited in Belyi, 1967/1999, p. 117).

Because many of the examples in this paper have clarified many aspects of meaning and those are then assumptions can be drawn as follows: meaning and an Linguistics, meaning and context of the Semantic, Behaviourist word, and Ambiguous notions of meaning are as a weak point in language study because when people speak and pronounce an expression, it has many meanings and makes people a weak point in language study. And the meaning of the sentence depends on the situation because sometimes people cannot understand the meaning or misinterpret it. Because so, it means as a weak point in language study based on the aspects listed above.

\section{Acknowledgement}

This research was supported by SMAN 2 Kampar. Therefore, the authors would like to express their sincere gratitude. Any opinions, findings, and conclusions or suggestions expressed in this material are those of the authors and do not necessarily reflect the views of the respected institution.

\section{References}

Belyi, Vilen Viktorovitch. (1999). Some Facts about Weiss's Influence on Bloomfield. In John Fought (Ed.), Leonard Bloomfield: Critical Assessment of Leading Linguists Vol. 2 (pp. 115-118). London: Routledge.

Bloomfield, L. (1930). Linguistics as a Science. Studies in Philosophy, 27(4), 553-557.

Bloomfield, L. (1933). Language. Beijing: Foreign Language Teaching and Research Press.

Bloomfield, L. (1935). Linguistic Aspects of Science. Philosophy of Science, 2(4), 499-517.

Bloomfield, L. (1936). Language or Ideas? Language, 12(2), 89-95.

Bloomfield, L. (1939). Linguistic Aspects of Science. International Encyclopedia of Unified Science 1 (4). Chicago: University of Chicago Press.

Bloomfield, L. (1943). Meaning. Monatshefte fur Deutschen Unterricht, 35, 101-106.
Bloomfield, L. (1949). Linguistic aspects of science. International encyclopedia of united science I 14. Chicago: University of Chicago Press.

De Beaugrande, R. (1991). Linguistic theory: the discourse of fundamental works. London: Group ltd.

Firth, J. R. (1957a). Papers in linguistics $1934-1951$. London: OUP.

Hamuddin, B. (2016). Using Content Analysis (CA) in Seeking the Opportunities for Alumni of English Department in Newspapers. ELTLectura, 3(1).

Lexy,, J.Moleong. (2005). Metodologi Penelitian Kualitatif. Bandung : PT. Remaja Rodakarya.

Mhute, I. et al. 2014. Introduction to General Linguistics II. Harare: ZOU

Moleong, J.L. (2000). Metodologi Penelitian Kualitatif. Bandung : PT. Remaja Rodakarya.

Mutarcim. Veysalli, F. Y. (2013). The bases of Linguistics. Studia Philologica VI. Baku: Mutarjim.

Syal, P. and Jindal, D.V . An Introduction to Linguistics: Language, Grammar and Semantics. New Delhi: Prentice Hall

Ullman, S. (1962). Semantics: an introduction to the study of meaning. Oxford: Basil Blackwell.

Veysalli, F. Y. (2008). The bases of Structural linguistics II. Studia Philologica II. Baku:

Wang Yuanxin. (2006). Theories of Language and Methodologies of Linguistics. Beijing: Educational Science Publishing House.

Xiong Bin. (2007). American Structural Linguistics and Modern Chinese Grammar Research. Wuhan: Central China Normal University Press.

Yin, Xiujuan. (2008). Probe into Bloomfield's "Meaning". Journal of Anhui University of Technology (Social Sciences), 25(4): 84-85, 110.

Fromkin, V., Rodman, R., \& Hyams, N. (2018). An introduction to language. Cengage Learning.

Andrews, M., Frank, S., \& Vigliocco, G. (2014). Reconciling embodied and distributional accounts of meaning in language. Topics in cognitive science, 6(3), 359-370.

Nelson, K. (2014). Concepts and meaning in language development. In Biological and behavioral determinants of language development (pp. 99-126). Psychology Press. 